\title{
Bidirectional interaction between intestinal microbiome and cancer: opportunities for therapeutic interventions
}

\author{
Dibyendu Dutta ${ }^{1,2}$ and Seah H. Lim ${ }^{1,2^{*}}$ (i)
}

\begin{abstract}
Gut microbiota composition influences the balance between human health and disease. Increasing evidence suggests the involvement of microbial factors in regulating cancer development, progression, and therapeutic response. Distinct microbial species have been implicated in modulating gut environment and architecture that affects cancer therapy outcomes. While some microbial species offer enhanced cancer therapy response, others diminish cancer treatment efficacy. In addition, use of antibiotics, often to minimize infection risks in cancer, causes intestinal dysbiosis and proves detrimental. In this review we discuss the role of gut microbiota in cancer development and therapy. We also provide insights into future strategies to manipulate the microbiome and gut epithelial barrier to augment therapeutic responses while minimizing toxicity or infection risks.
\end{abstract}

Keywords: Intestinal dysbiosis, Cancer development, Cancer therapy, Microbial therapy

\section{Background}

Human intestinal microbiota is essential for microbial homeostasis, regulation of metabolism, and immune tolerance. Intestinal dysbiosis occurs when there are altered ratios of healthy microbial flora along with changes in their diversity and density. Such changes may lower mucus layer thickness, reduce antimicrobial defense, and disrupt the epithelial tight-junction barriers to allow increased translocation of intestinal bacteria and bacterial products into the systemic circulation and trigger inflammation and immune responses. Circulating bacterial products such as endotoxin, genotoxin and trimethylamine oxide have been implicated in many human disorders, including metabolic syndrome, cardiovascular complications (atherosclerosis and thrombosis), and various neoplastic conditions. Intestinal dysbiosis may also affect adaptive immunity by

\footnotetext{
* Correspondence: seahhlim@yahoo.com

'Division of Hematology and Oncology, SUNY Downstate Health Sciences University, 450 Clarkson Avenue, Room B5-495, Brooklyn, New York 11203, USA

2Division of Hematology and Oncology, Department of Medicine, New York Medical College, Valhalla, New York, USA
}

modulating the functions of $\mathrm{T}$ lymphocytes and promoting tumor immune escape.

While increased translocation of intestinal luminal content is associated with carcinogenesis and poor therapeutic response, the cause-effect relationship is often bidirectional. In this review we will discuss the role of gut microbes in modulating tumor immunity, intestinal permeability and cancer development. Next, we will highlight the effects of intestinal dysbiosis and increased permeability in cancer therapy. Finally, we will explore the options to improve gut health to enhance the efficacy of cancer therapy.

\section{Intestinal immunity and permeability}

The intestinal architecture and microbiota regulate innate and adaptive immunity. Disruption of the architecture and/or microbiota affects these functions. The relationships between the different players in the intestinal microenvironment is summarized in Fig. 1.

The composition of microbes in the gut dictates mucus layer thickness and production of anti-microbial signals. In germ-free mice, mucus layer and effector $\mathrm{T}$

(c) The Author(s). 2020 Open Access This article is licensed under a Creative Commons Attribution 4.0 International License, which permits use, sharing, adaptation, distribution and reproduction in any medium or format, as long as you give appropriate credit to the original author(s) and the source, provide a link to the Creative Commons licence, and indicate if changes were made. The images or other third party material in this article are included in the article's Creative Commons licence, unless indicated otherwise in a credit line to the material. If material is not included in the article's Creative Commons licence and your intended use is not permitted by statutory regulation or exceeds the permitted use, you will need to obtain permission directly from the copyright holder. To view a copy of this licence, visit http://creativecommons.org/licenses/by/4.0/ The Creative Commons Public Domain Dedication waiver (http://creativecommons.org/publicdomain/zero/1.0/) applies to the data made available in this article, unless otherwise stated in a credit line to the data. 

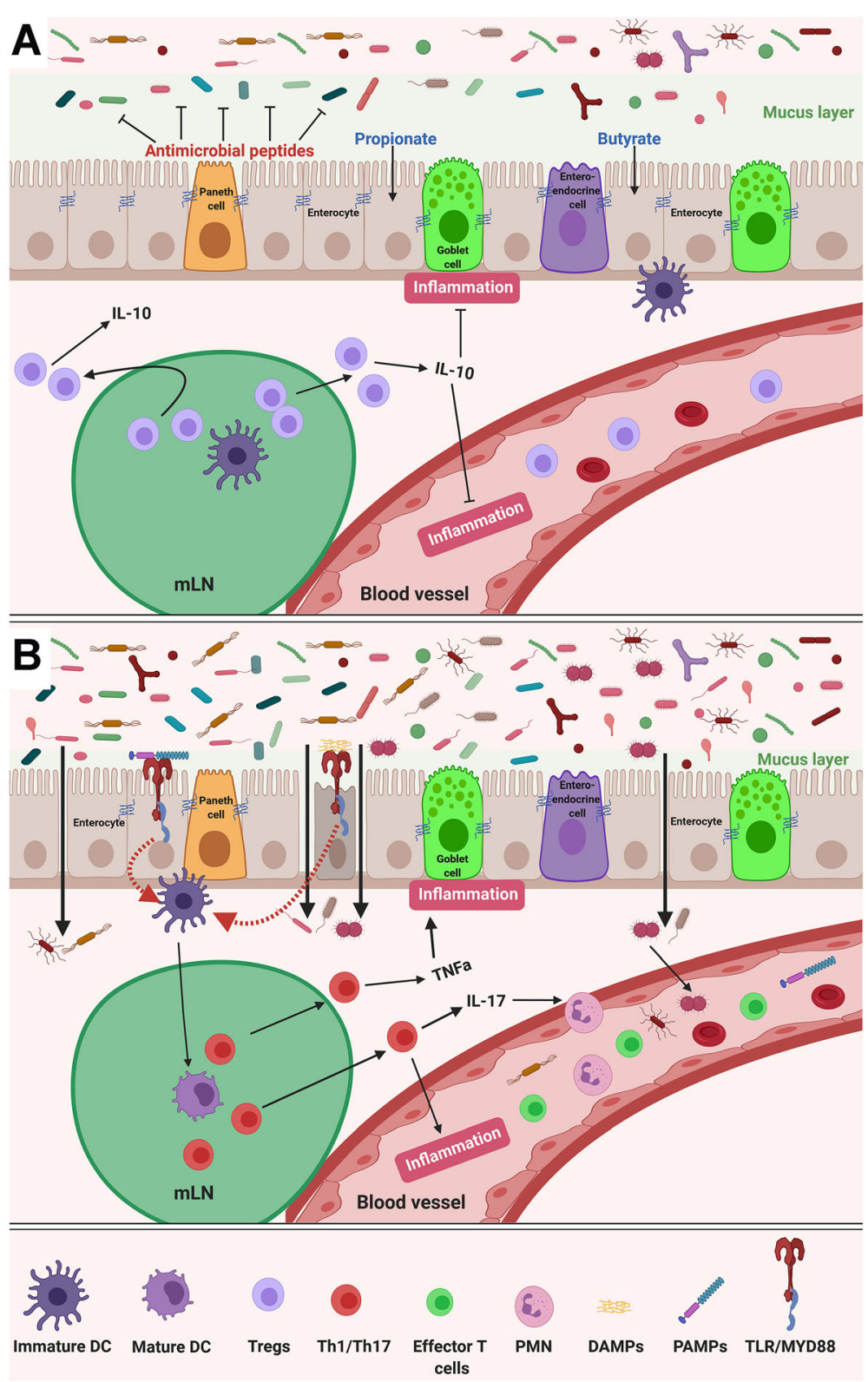

Fig. 1 Interplay between different factors involved in gut immunity and permeability. a The intestinal epithelial cells containing Paneth cells, goblet cells, enterocytes and enteroendocrine cells coordinate with intra-epithelial lymphocytes to generate a functional immune response. Paneth cells secrete antimicrobial peptides and goblet cells produce mucus to cover the epithelial layer. This mucus layer prevents adhesion of microbes to the epithelial cells. Lamina propria situated under the mucus layer contains Peyer's patches and immune cells including antigen presenting cells (APCs) like dendritic cells (DCs), T cells and B cells. Pattern recognition receptors (PRRs) such as toll-like receptors (TLRs) on epithelial cells interact with microbe-derived pathogen-associated-molecular patterns (PAMPs) such as lipopolysaccharide (LPS) to activate MYD88-dependent signaling. DCs travel to mesenteric lymph nodes $(\mathrm{mLN})$ and promote the differentiation of naive $T$ cells to regulatory $T\left(T_{\text {reg }}\right)$ cells that migrate to other sites. Treg cells secrete IL-10 to elicit an anti-inflammatory response. $\mathbf{b}$ Dysbiosis decreases mucus layer thickness and short-chain fatty acid (SCFAs) production. This affects the secretion of antimicrobial peptides and allows microbes to come in close proximity to the epithelial cells. Reduction in SCFAs influences gut barrier dysfunction. As a result, the gut luminal content also translocated and spreaded through the systemic circulation to trigger local and systemic immune responses. In addition to PAMPs, DAMPs released from damaged intestinal epithelium interact with PRRs to facilitate expression of macrophages and maturation of DCs. Mature DCs promote the differentiation of naïve $T$ cells to effector T cells such as T helper cells (Th1, Th2, Th17). Th1 release TNFa and IFNy, and Th17 secrete IL-17 to recruit polymorphonuclear neutrophils (PMNs). These cytokines create a pro-inflammatory condition 
cells are absent [1,2]. Microbes secrete short-chain fatty acids (SCFAs) such as propionate and butyrate that prevent microbial binding to the epithelial cells and help maintain barrier function and immune homeostasis. Butyrate promotes tight-junction formation [3, 4], and activates peroxisome proliferator-activated receptor gamma (PPAR- $\gamma$ ) to enhance epithelial oxygen consumption, resulting in reduced emanation of oxygen from the mucosal surface. It helps in maintaining an anaerobic condition in the gut lumen needed for colonization of obligate anaerobes [5]. This intestinal microenvironment determines the composition of resident bacterial species. For example, only Clostridium, Lactobacillus and Enterococcus are enriched on the epithelial surface and in the mucus layer, whereas Bacteroides, Bifidobacterium, Streptococcus, Enterobacteriaceae, Enterococcus, Clostridium and Lactobacillus are all predominant in the intestinal lumen [6].

Dysbiosis increases inflammatory signals that shift the metabolism of enterocytes. Epithelial hypoxia is eliminated and increased oxygenation results in the release of more oxygen from the mucosal surface. Since only facultative anaerobes can respire oxygen, dysbiosis-induced shift in epithelial oxygenation alters gut microbial community from obligate to facultative anaerobes [5]. Intestinal pathogens, such as Proteobacteria, produce genotoxins like colibactin and cytolethal distending toxin (CDT) to induce inflammation and host deoxyribonucleic acid (DNA) damage that initiates tumor formation [7]. Dysbiosis also decreases mucus layer thickness, reduces SCFA production, and damages mucosal barrier, allowing pathogen-associatedmolecular patterns (PAMPs) to interact with pattern recognition receptors (PRRs) and activate Toll-like receptor (TLR) 2/4-Myeloid differentiation primary response protein 88 (MYD88) signaling pathways. In addition, changes in microbial composition and density triggers epithelial release of damage-associated molecular patterns (DAMPs), such as extracellular adenosine triphosphate (ATP), cytoplasmic calreticulin, high mobility group box 1 (HMGB1) proteins, endogenous nucleic acids, and intracellular proteins to interact with PRRs. PRR engagement triggers a proinflammatory condition that causes tissue damage and local inflammation. Microbiota-driven TLR immune signaling has been implicated in cancer formation and modification of treatment efficacy [8-11]. For example, CpG oligodeoxynucleotides that mimic bacterial DNA acts as a PAMP to trigger a TLR9-dependent TLR4 activation and tumor necrosis factor (TNF)- $\alpha$ production by tumor-infiltrating myeloid-derived cells [12]. Mice bearing EL4 lymphoma, MC38 colon carcinoma and B16 melanoma when treated with CpG oligodeoxynucleotides show reduced tumor growth and enhanced survival rate. The beneficial effects of CpG oligodeoxynucleotides were positively associated with the abundance of Alistipes shaii in the gut [12].

\section{Effects of intestinal microbiota on cancer development}

Intestinal microbes can influence local and distant carcinogenesis through infection and microbial products, or by modulating tumor immunosurveillance. This is accomplished via altering the balance between the rate of cell proliferation and apoptosis, triggering chronic inflammation and/or immunosuppression, or changing the metabolism of the products produced by host and microbes. In this section, we will discuss how intestinal dysbiosis-related permeability may contribute to tumorigenesis in different organs.

\section{Colorectal cancer}

Fusobacterium nucleatum, a Gram-negative mucosaadherent anaerobic bacteria, has been implicated in the initiation and progression of colorectal cancer (CRC) $[13,14]$. FadA, an adhesion molecule on $F$. nucleatum, binds to host E-cadherin to enter epithelial cells [13]. This activates the $\mathrm{WNT} / \beta$-catenin pathway, leading to an increased secretion of inflammatory cytokines including IL-6, IL- 8 and TNF- $\alpha$, and upregulation of Nuclear Factor kappa light chain enhancer of activated B cells (NF-KB) that facilitates CRC development. In addition, it attracts myeloid-derived suppressor cells and the autotransporter protein Fap2 interacts with the human inhibitory receptor, $\mathrm{T}$ cell immunoreceptor with $\mathrm{Ig}$ and ITIM domains (TIGIT), to create a tumor immunosuppressive microenvironment. F. nucleatum may also induce chemoresistance by modulating the TLR4-MYD88 signaling pathway following 5-Fluoruracil treatment [11].

In CRC patients, an increased abundance of F. nucleatum along with Clostridium difficile and species of Streptococcus, Campylobacter and Leptotrichia has been demonstrated in tumor tissue and fecal materials [15-17]. F. nucleatum-mediated colorectal carcinogenicity occurs downstream of APC. Introduction of $F$. nucleatum resulted in rapid onset of colonic tumors in mice deficient in one copy of Adenoma Polyposis coli (APC) $\left(A p c^{\mathrm{Min} /+}\right)$ gene [14]. Both intestinal dysbiosis and loss of APC disrupt epithelial tight-junctions and mucus layer [18, 19] and allow increased infiltration of $F$. nucleatum and other nonresidential microbes to drive CRC development. The role of defective gut barrier in CRC has been confirmed in mucin 2-knockout $\left(\mathrm{Muc2}^{-/-}\right)$mice in which the lack of gastrointestinal mucin resulted in spontaneous CRC development [20]. Therefore, dysbiosis-induced gut permeability may play an important role in tissue enrichment of $F$. nucleatum and increased risks for CRC.

\section{Hepatobiliary cancer}

The liver is chronically exposed to intestinal microbiota and its products via the portal vein. Intestinal dysbiosis and increased permeability enhance translocation of gut 
microbiota to trigger inflammation and chronic liver disease that predisposes patients to the development of hepatocellular cancer. Alteration in bile acid metabolism due to changes in Clostridium spp. suppress anticancer immunity [21]. In mice, eradication of Gram-positive bacteria by oral vancomycin inhibits secondary bile acid conversion, resulting in the upregulation of chemokine (C-X-C motif) ligand (CXCL)16 in liver sinusoidal endothelial cells. CXCR16 recruits natural killer $\mathrm{T}$ (NKT) cells in the tumor microenvironment and kill tumor cells in a CD1d-dependent manner. In addition, gut microbiota-derived lipopolysaccharides (LPS) promote tumor progression in liver cancer by activating the TLR4 signaling [8]. In a study involving 60 cholangiocarcinoma patients, bile duct tissues had distinct dominance of Dietziaceae, Pseudomonadaceae and Oxalobacteraceae members [22].

\section{Pancreatic cancer}

Gut microbiota influences the development of pancreatic cancer through activating TLR4 signaling [23]. The stroma in pancreatic tumor harbors an abundance of microbiota, especially Bifidobacterium pseudolongum, compared to normal pancreas [24]. This helps in creating an immunosuppressive environment by differentially activating distinct TLRs in monocytes. Pancreatic adenocarcinoma has an enrichment of Proteobacteria, Synergistetes, and Euryarchaeota [24]. Longer survival is observed in patients with a more diverse intratumor microbial composition, primarily of Sachharopolyspora, Pseudoxanthomonas, Streptomyces, and Bacillus clausii [25]. Tumoral colonization with Mycoplasma hyorhinis and Gammaproteobacteria is associated with gemcitabine resistance [26]. Antibiotics diminish myeloid-derived suppressor cells and increase antitumor M1 macrophages to promote Th1 differentiation of $\mathrm{CD} 4^{+}$ $\mathrm{T}$ cells and $\mathrm{CD}^{+} \mathrm{T}$ cell activation in the tumor [24]. Cotreatment of gemcitabine with ciprofloxacin abrogated Gammaproteobacteria-induced chemotherapy resistance [26]. The efficacy of immune checkpoint inhibitors (ICIs) therapy is also enhanced by antibiotics [24].

\section{Lung cancer}

While local microbiota is important [27], there are reports that gut microbiome may also contribute to lung cancer development. Lung cancer patients demonstrated an abundance in intestinal Enterococcus and depletion in Bifidobacterium and Actinobacteria [28]. They are also enriched with Veillonella, Bacteroides, and Fusobacterium, depleted of Dialister, Enterobacter, Escherichia-Shigella, Fecalibacterium, and Kluyvera [29]. In non-small cell lung cancer (NSCLC) patients, butyrate producers such as Faecalibacterium prausnitzii, Clostridium leptum, Clostridial cluster I, Ruminococcus spp., Clostridial cluster XIVa, and Roseburia spp. were significantly reduced [30]. Since butyrate is essential for preserving mucosal homeostasis, reduction of intestinal butyrate producers may imply a compromised intestinal barrier in these patients.

\section{Hematologic malignancies}

Dysbiosis-induced intestinal permeability affects mucosaassociated lymphoid tissue (MALT) and plays a significant role in hematologic malignancies. Composition of intestinal microbiota is responsible for maintaining the pool of bone marrow myeloid cells [31]. Pre-leukemic myeloproliferation is driven by microbial signals in ten-eleven translocation-2 (Tet2)-deficient mice [32, 33]. These mice show increased infiltration of inflammatory cells, disrupted mucosal barrier and increased translocation of bacteria [32, 34]. It was suggested that dysfunction of small intestinal barrier and leakage of microbes can occur due to Tet 2 mutation in hematopoietic compartment [32]. Occurrence of Tet2 mutation, intestinal dysbiosis and leaky gut is common in leukemia and lymphoma.

Acute myeloid leukemia (AML) and acute lymphoblastic leukemia (ALL) patients have a compromised intestinal barrier [35-37]. Fecal microbiota in ALL patients showed lower microbial diversity [38]. They were enriched in Enterococcaceae, Porphyromonadaceae, and Bacteroidetes (mainly B. fragilis), and depleted in Blautia, Erysipelotrichiales, Lachnospiraceae and Clostridiales members [39, 40]. Abundance of Staphylococcaceae and Streptococcaceae have also been reported in pediatric ALL and adult AML [41, 42].

Helicobacter pylori is associated to MALT lymphoma [43], and Chamydophila psittaci to ocular MALT lymphoma [44]. While Borrelia burgdorferi was linked to cutaneous B-cell non-Hodgkin lymphoma [45], two studies did not find significant risk of Borrelia burgdorferi in the development of non-Hodgkin lymphoma [46, 47]. Abundance of Proteobacteria is a predictor for neutropenic fever, and enrichments of Enterococcaceae and Streptococcaceae are strong predictors of infectious complications in ALL [42]. Similarly, higher gut microbiota diversity in multiple myeloma is associated with reduced risk for disease relapse [48]. ALL patients with infectious complications have an abundance of Brevundimonas diminuta and Agrobacterium tumefaciens, whereas Faecalibacterium prausnitzii (producer of SCFAs) is completely absent [49]. Similar findings have been reported in non-Hodgkin lymphoma with infectious complications [50].

\section{Effects of intestinal microbiota on cancer therapy}

The efficacy of cancer treatment is, in parts, dependent on normal immune function. Since gut microbiota plays a crucial role in modulating immune response, it is not surprising that dysbiosis affects treatment outcomes. Prophylactic antibiotics are commonly used for cancer patients undergoing chemotherapy and allogeneic hematopoietic stem cell transplantation (allo-HSCT) to reduce the risk of neutropenia-associated infection. 
However, antibiotic use causes intestinal dysbiosis that results in negative outcomes, including poor treatment response and toxicity, and the development of Clostridium difficile infection (CDI). In addition to antibiotics, opioid analgesics for cancer pain management may also trigger dysbiosis. Opioid analgesics impair intestinal motility and promote bacterial overgrowth resulting in dysbiosis and gut permeability [51].

Intestinal dysbiosis induces mucosal injury and triggers the release of DAMPs. DAMPs have a dual and bidirectional effect on cancer. Although DAMPs exert immunosurveillance and immune-mediated cell death to eliminate tumor cells and protect against cancer development, chronic inflammation induced by DAMPs may promote tumor initiation. DAMPs released by apoptotic cells from cancer therapy may also induce chemoresistance and promote metastasis. For example, TLR7/8 expressed on tumor cells may bind DAMPs (loxoribine for TLR7, and poly U for TLR8) and promote chemoresistance through the activation of NF- $\mathrm{KB}$ and the upregulation of BCL2 [52]. DAMPs may also activate TLR9 on human breast, prostate and lung cancer cells to trigger tumor invasion and metastasis [53, 54]. Given the clinical significance of dysbiosis-mediated mucosal injury and permeability in cancer, we will, in this section, discuss how the treatment outcome by various cancer therapy may be affected by intestinal microflora and permeability.

\section{Chemotherapy and radiation therapy}

Intestinal microbial composition and mucosal barrier function influence chemotherapeutic outcome, and the effect is bidirectional. While dysbiosis can exacerbate chemotherapy drug toxicity and reduce its efficacy, chemotherapy can itself cause dysbiosis. Although, prevalence of certain intestinal microbes in the gastrointestinal tract offer beneficial effects, others contribute to chemoresistance and drug toxicity. This multiple-pathway effect is best covered by TIME $\mathrm{R}$ mechanisms [55] - Translocation of microbes; Immunomodulation; $\underline{M}$ etabolism and $\underline{e n z y m a t i c}$ effects on drugs; and $\underline{R}$ educed microbial diversity. These mechanistic effects alter chemotherapy efficacy and toxicity, and risks for infections. For example, translocation of microbes due to chemotherapy induced-dysbiosis and disruption of mucosal barrier can increase the risk of infection. However, certain chemotherapy drugs such as cyclophosphamide and doxorubicin damage intestinal barrier for the translocation of commensal bacteria into secondary lymph nodes to elicit anti-tumor immune response [55]. Vancomycin prophylaxis inhibits antitumor effects of cyclophosphamide in fibrosarcoma inoculated mice [56]. Irinotecan, used for CRC treatment, is transformed into its active form $\mathrm{SN}-38$ by tissue carboxylesterase [55]. It is detoxified in the liver by host UDP-glucuronosyltransferases into inactive glucuronide (SN-38-G) and excreted into the gut via bile ducts. In the gut, bacterial $\beta$-glucuronidases reconverts SN-38-G into active SN-38, which causes severe intestinal toxicity and diarrhea [57]. Streptomycin inhibits irinotecan absorption and reduces epithelial carboxylesterase activity and diarrhea [58]. Ciprofloxacin inhibit $\beta$-glucuronidases $[59]$ and low dose amoxapine ( $\beta$-glucuronidases inhibitor) suppress irinotecan-associated diarrhea in rats [60]. Table 1 provides a selection of chemotherapeutic agents affecting and affected by intestinal microbial composition and permeability.

Local pelvic irradiation damages intestinal epithelium and barrier integrity and produce reactive oxygen species. Irradiation increase Alistipes and decrease Prevotella in mice [80]. In gynecologic cancer patients receiving pelvic radiotherapy, Firmicutes and Fusobacterium were significantly decreased [81]. In addition to reduced diversity, significant enrichment of Clostridium IV, Roseburia, and Phascolarctobacterium was associated with radiation enteropathy in pelvic cancer patients [82]. The effects of total body irradiation, which is a preparative regimen for allo-HSCT that causes dysbiosis and gastrointestinal toxicity, is discussed in more details in the allo-HSCT section below.

\section{Immunotherapy}

Cancer cells often create an immunosuppressive microenvironment to mediate tumor immune escape. This immune escape mechanism may be reversed by ICIs directed at cytotoxic $\mathrm{T}$ lymphocyte-associated antigen 4 (CTLA-4), programmed death receptor 1 (PD-1), or PD-1 ligands (PD-L1). Since intestinal microbes influence local and systemic antitumor immune reaction by modulating PRRs, PAMPs and DAMPs, intestinal dysbiosis may impact treatment outcome. Figure 2 illustrates how the potential mechanisms of the antitumor immune responses are downregulated by intestinal dysbiosis. The effects of intestinal microbiome on responses to ICIs have been discussed previously [83, 84]. Broad-spectrum antibiotics before, during, or after ICIs therapy alter intestinal microbiome and resulted in lower tumor response rate, inferior progression-free survival and reduced overall survival [85].

Responses to inhibition of CTLA-4 by ipilimumab in mouse models of MCA205 sarcoma, RET melanoma, and MC38 colon carcinoma were inferior in germ-free or in broad-spectrum antibiotic treated mice [86]. Poor responses were associated with decrease in intestinal Bacteroides thetaiotaomicron, Bacteroides uniformis and Burkholderia cepacia, and increase in Clostridiales. Such dysbiosis was also associated with mucosal damage and colitis. Oral feeding with either Bacteroides thetaiotaomicron or Bacteroides fragilis individually, or with a combination of Bacteroides fragilis and Burkholderia cepacia restored the antitumor effects of CTLA-4 blockade through augmentation of Th1 responses in tumor- 
Table 1 Selection of chemotherapeutic agents and the bidirectional effects between the chemotherapy and intestinal microbiota

\begin{tabular}{|c|c|c|c|}
\hline Chemotherapy Drug & Effects on Gut/ Changes in Microbiota & Toxicity/Infection & Microbial Intervention \\
\hline Cisplatin & $\begin{array}{l}\text { Damages mucosal barrier by impairing DNA } \\
\text { replication of rapidly proliferating epithelial } \\
\text { cells [61] } \\
\text { Facilitates translocation of gut bacteria } \\
\text { Commensal gut bacteria influences } \\
\text { genotoxicity by inducing reactive oxygen } \\
\text { species (ROS) production and recruitment of } \\
\text { pathogenic Th17 cells in the tumor } \\
\text { microenvironment independently of } \\
\text { immunity elicited by immunogenic cell } \\
\text { death [12] }\end{array}$ & $\begin{array}{l}\text { CDI [62] } \\
\text { Ototoxicity [63] }\end{array}$ & $\begin{array}{l}\text { Antibiotics against Gram-positive bacteria } \\
\text { abrogate antitumor chemotoxicity, } \\
\text { increase tumor size and decrease survival } \\
\text { rate } \\
\text { Cisplatin alone show better response } \\
\text { compared to a combined treatment of } \\
\text { cisplatin and antibiotics in mice with lung } \\
\text { cancer [64]. The combination treatment } \\
\text { increased tumor size and decreased } \\
\text { survival rate } \\
\text { Lactobacillus acidophilus restores antitumor } \\
\text { efficacy following antibiotic treatment } \\
\text { [64, 65] } \\
\text { Restoration of gut microbiota and } \\
\text { epithelial integrity by FMT [66] and } \\
\text { treatment with D-methionine [67, 68] } \\
\text { prevent infections and ototoxicity without } \\
\text { affecting tumor chemotoxicity }\end{array}$ \\
\hline Paclitaxel & $\begin{array}{l}\text { Increases gut permeability, as indicated by } \\
5 \text {-fold elevation in circulating LPS-binding } \\
\text { protein and systemic inflammation [69] } \\
\text { Reduces abundance of Roseburia, } \\
\text { Porphyromonadaceae and Akkermanisa } \\
\text { Muciniphila }[69,70]\end{array}$ & $\begin{array}{l}\text { Chemotherapy-induced } \\
\text { peripheral neuropathic } \\
\text { pain (CIPN) [70] } \\
\text { CDI }[71,72]\end{array}$ & $\begin{array}{l}\text { FMT increases A. Muciniphila } \\
\text { abundance and reduces CIPN [70] }\end{array}$ \\
\hline 5-Fluoruracil & $\begin{array}{l}\text { Reduces Clostridium spp. and increases } \\
\text { members of Proteobacteria, mainly } \\
\text { Enterobacteriaceae [73] } \\
\text { Damages mucosal barrier }\end{array}$ & $\begin{array}{l}\text { Mucositis along the entire } \\
\text { gastrointestinal tract }[74] \\
\text { CDI }[75,76]\end{array}$ & $\begin{array}{l}\text { Oral butyrate supplementation improves } \\
\text { gut barrier by reducing inflammation and } \\
\text { mucositis [77] } \\
\text { Antibiotics reduce mucositis and cytokine } \\
\text { production but also diminish antitumor } \\
\text { efficacy [78] and promote chemotherapy } \\
\text { resistance [11] }\end{array}$ \\
\hline Cyclophosphamide & $\begin{array}{l}\text { Triggers disruption of gut barrier by altering } \\
\text { bacterial composition } \\
\text { Gram-positive bacteria such as } \\
\text { Enterococcus hirae, Lactobacillus johnsonii, } \\
\text { and L. murinus translocate from gut into } \\
\text { mesenteric lymph nodes and spleen [56]. } \\
\text { This enhances immune responses by the } \\
\text { production of interferon gamma (IFN- }-\gamma \text { ) and } \\
\text { activation of Th17 cells }\end{array}$ & CDI [75] & 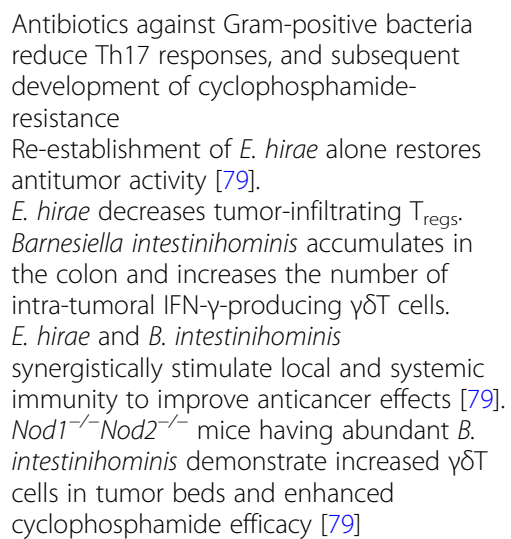 \\
\hline
\end{tabular}

draining lymph nodes and promotion of maturation of intra-tumoral dendritic cells (DCs). In addition, the combination treatment of Bacteroides fragilis and Burkholderia cepacia prevented intestinal damage and refractory colitis.

Fecal microbiota analysis of melanoma patients before and after ipilimumab treatment showed a change in the relative proportions of three dominant enterotype clusters [86]. Cluster A was dominated by Prevotella sp., whereas clusters $\mathrm{B}$ and $\mathrm{C}$ by different Bacteroides spp. Fecal microbiota transplantation (FMT) from patients into tumor-bearing, germ-free mice showed that only fecal material from cluster $\mathrm{C}$ resulted in colonization with Bacteroides thetaiotaomicron or Bacteroides fragilis, and enhanced ipilimumab response. In another study of ipilimumab in mice, vancomycin treatment resulted in a more severe manifestation of colitis, whereas oral administration of Bifidobacterium ameliorated the side effects [87]. Similarly, melanoma patients with increased abundance of Bacteroidaceae, Rikenellaceae, and Barnesiellaceae members responded better to CTLA-4 antibodies [88].

However, a different study in ipilimumab-treated melanoma patients found that Bacteroides spp. were associated with decreased response, whereas Faecalibacterium and other Firmicutes members improved clinical outcome 

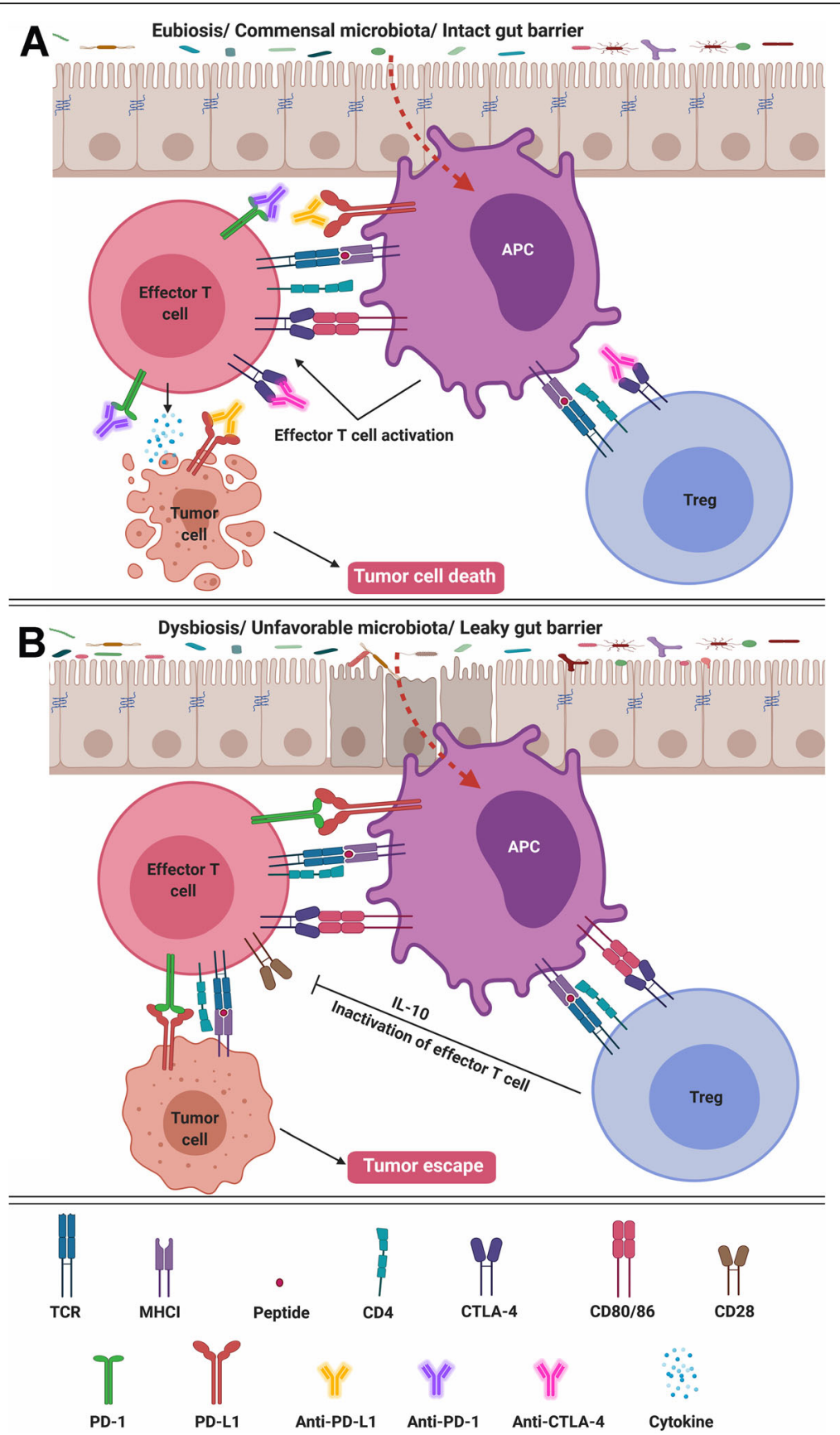

Fig. 2 Potential antitumor immune mechanisms induced by intestinal dysbiosis. a In the presence of intact mucosal barrier and signals from commensal microbiota, effector T cell activation is modulated by T cell receptor (TCR) ligation with major histocompatibility complex (MHC) class I, and co-stimulation of CD80/CD86 and CD28. Binding of cytotoxic T lymphocyte-associated antigen 4 (CTLA-4) receptor to anti-CTLA-4 antibody on $T_{\text {reg }}$ impairs its effector T-cell inhibitory function. It also downregulates CTLA-4 expression on APC. Ligation of repressive receptor programmed death receptor 1 (PD-1) and its ligand PD-L1 to anti-PD-1 and anti-PD-L1 antibodies, respectively, activate effector T-cell proliferation and function. Activated effector T cells interact with tumor cells and release cytokines to induce tumor cell death. $\mathbf{b}$ Signals from unfavorable microbes due to dysbiosis upregulates CTLA-4, PD-1 and PD-L1 expression to inhibit T-cell activation. CTLA-4 on Treg binds to CD80/CD86 on antigen presenting cell (APC). CD80/CD86 on APC also dis-engages from CD28 and binds to CTLA-4 on effector T cells. PD-L1, the ligand of PD-1, is expressed on antigen presenting cell (APC) and tumor cells. PD-1 on effector T cells ligates to PD-L1 on APC and tumor cells. These activities inhibit effector T-cell activation, reduces immune checkpoint inhibitor (ICI) efficacy, and causes tumor escape 
[89]. Patients with higher abundance of Faecalibacterium and improved response to CTLA-4 antibodies showed higher incidence of enterocolitis and lower level of $\mathrm{T}_{\text {reg }}$ in peripheral blood. Thus, the beneficial effects of specific and isolated gut microbes may depend on the commensal association with other microbial species and may differ between humans and mice.

PD-1 blockade may also be modulated by intestinal microbiota. Melanoma patients who responded to PD-1 blockade had increased abundance of Enterococcus faecium, Collinsella aerofaciens, Bifidobacterium adolescentis, Klebsiella pneumoniae, Veillonella parvula, Parabacteroides merdae, Lactobacillus sp., and Bifidobacterium longum, whereas in non-responders, the intestinal microbiome was enriched in Ruminococcus obeum and Roseburia intestinalis [90]. Another study found higher abundance of Faecalibacterium species in responders, and enrichment with Bacteroides thetaiotaomicron, Escherichia coli, and Anaerotruncus colihominis in non-responders [91]. Clinically, non-small cell lung cancer (NSCLC) and renal cell carcinoma (RCC) patients experienced increased resistance to PD-1 blockade after antibiotic treatment [92]. These patients had shorter progression-free survival as well as overall survival. In this study, response to PD-1 blockade correlated with higher fecal abundance of Akkermansia muciniphila. FMT from responders to germ-free or antibiotic-treated mice improved the outcome of PD-1 blockade. Administration of A. muciniphila after FMT from non-responders restored response.

Similarly, intestinal microbiota may influence the outcome of chimeric antigen receptor $\mathrm{T}$ cell (CAR T) therapy. Patients with complete response to CD19 CAR T-therapy exhibited enrichment of Oscillospiraceae, Ruminococcacaeae, and Lachnospiraceae in their intestinal microbiome, whereas patients who did not attain a complete response showed increased abundance of Peptostreptococcaceae [93].

\section{Allogenic hematopoietic stem cell transplantation}

Although allo-HSCT is effective in treating some hematological malignancies, the immunosuppressive agents, broad-spectrum antibiotics, and chemoradiation used with the transplant often induce intestinal dysbiosis, gut permeability and impaired systemic immune response. Higher microbiota diversity is associated with long-term survival, and lower diversity in gut microflora is associated with reduced overall survival and higher transplant-related mortality following allo-HSCT [94, 95]. Severe infections that occur due to intestinal dysbiosis, such as CDI and vancomycinresistant enterococci (VRE) infections, are also associated with higher treatment-related mortality [96-99]. Allo-HSCT disrupts the equilibrium of bacterial composition in feces with a dominance of Enterococcus, Streptococcus, and Proteobacteria members [100, 101], and reduces beneficial bacteria such as Faecalibacterium and Ruminococcus [102]. Higher abundance of Blautia was found to be associated with improved overall survival [103]. Moreover, allo-HSCT patients with reduced risk of relapse had an enrichment of Eubacterium limosum [48].

One of the major complications of allo-HSCT is the development of graft-versus-host disease (GvHD). Occurrence of CDI during allo-HSCT increases the risk of GvHD. Besides the loss of overall microbial diversity, reduction in beneficial Faecalibacterium, Blautia, Lactobacillus, and Ruminococcus, and increased abundance of Enterococcus and Clostridiales was observed in GvHD [102, 104-106]. Patients without GvHD had increased abundance of Parabacteroides and Bacteroides in their pre-transplant feces [102]. In a preclinical study, reduced GvHD and improved overall survival was observed after the administration of the probiotics Lactobacillus rhamnosus GG alone or in combination with ciprofloxacin due to the preservation of gut mucosal integrity in the recipient mice [105]. Restoration of normal intestinal microbiome by FMT has been found to benefit patients with steroid-refractory GvHD [107, 108]. Multiple clinical trials are currently ongoing to investigate how manipulation of gut microbiota using dietary intervention and FMT might reduce the risk of GvHD.

\section{Manipulation of intestinal microbiome and barrier to improve outcome of cancer therapeutics}

If intestinal dysbiosis and its associated increased gut permeability are associated with cancer development, and therapy-related complications, and treatment outcomes, it follows that intervention of the intestinal microbiome and/or gut barrier may alter cancer outcome. In this section, we will explore three broad approaches (Fig. 3) that might be investigated: 1) Non-selective modification of intestinal microbiome using FMT; 2) Semi-selective modification of intestinal microbiome using antibiotics; and 3) Biologic modification of intestinal barrier. We will discuss the challenges and obstacles each of the approaches may encounter.

\section{Non-selective modification of intestinal microbiome using FMT}

Modification of the intestinal microbiome is theoretically best accomplished by FMT. Unmanipulated FMT will not only replete the dysbiotic intestinal microbiome with the deficient microbes but also allow the re-establishment of a finely balanced microbial community. It may also reestablish/repair the intestinal barrier. FMT has been applied successfully to patients with antibiotic-resistant recurrent CDI [109-111]. Its restricted applicability due to the invasive nature of the treatment has recently been overcome with the introduction of capsule FMT. Preclinical studies have demonstrated the potential value of FMT in improving cancer outcome. Nod2-deficient mice that develop 


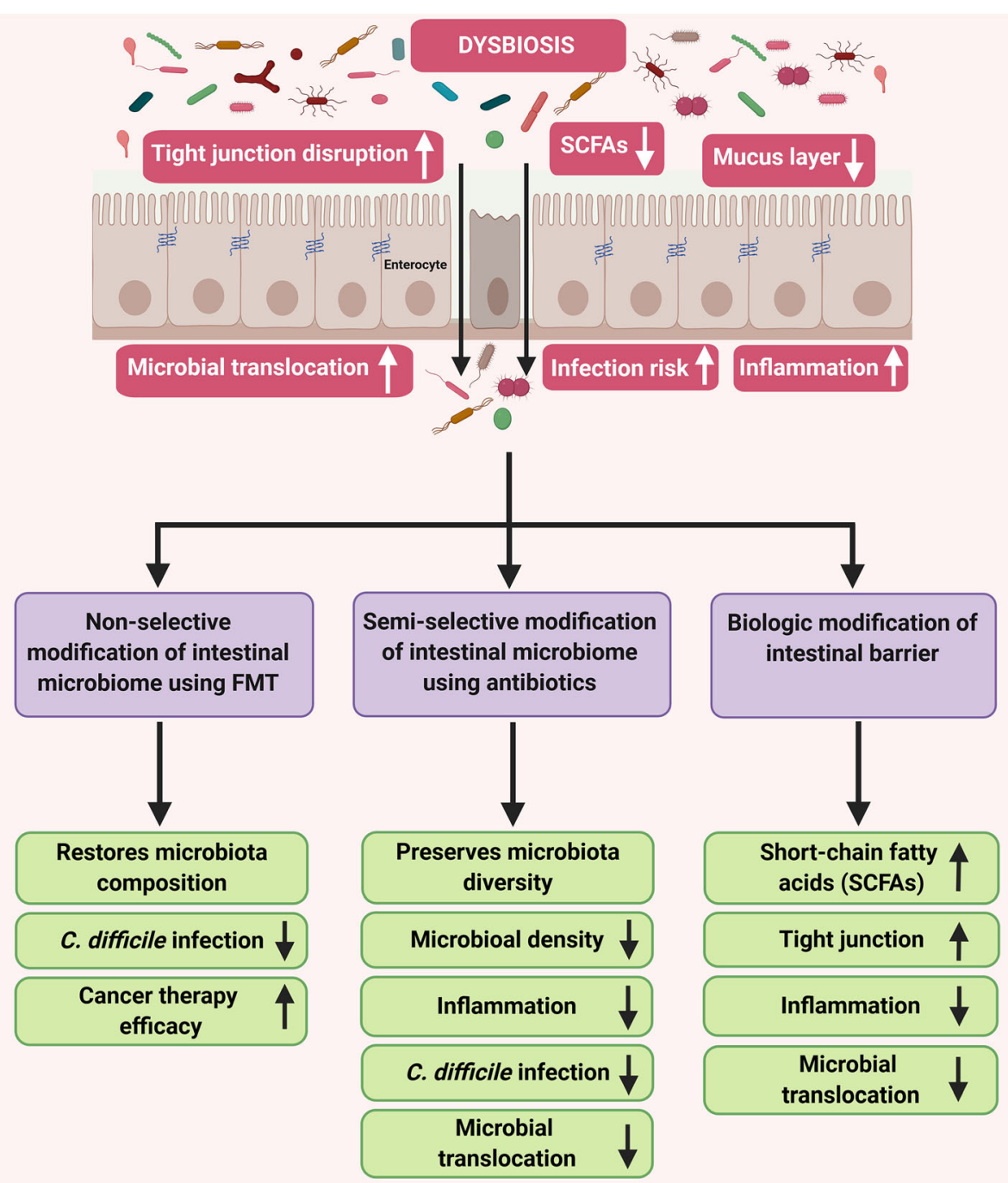

Fig. 3 Schematic representation of three approaches to manipulate intestinal microbiome and barrier to enhance cancer therapeutic outcomes. (Short-chain fatty acids (SCFAs); Fecal microbiota transplantation (FMT))

dysbiosis, spontaneous intestinal inflammation and increased risk of CRC, were partially protected from CRC after fecal transfer from wild-type mice [112]. When fecal material from metastatic melanoma patients undergoing anti-PD-1 therapy were transplanted into germ-free mice, feces enriched in Faecalibacterium species from responders elicited reduced tumor growth and improved anti-PD-1 treatment response [91]. Similar beneficial effects of FMT in immunotherapy efficacy were observed in NSCLC and RCC [92].

Steroid-refractory acute GvHD that occurred in patients who developed the complication following alloHSCT for hematologic malignancies responded to FMT, with resolution of the GVHD in most cases [107, 108]. FMT is also effective for refractory ICI-associated colitis in cancer patients [113] and recurrent CDI in allo-HSCT recipients [97, 99, 114]. Multiple clinical trials utilizing
FMT in cancer patients to improve chemotherapy or ICI efficacy in AML, metastatic melanoma, prostate cancer and RCC are underway.

Unmanipulated FMT, however, has its challenges. Serious and fatal infection may occur, especially in those with a compromised intestinal barrier. Two patients who received capsule FMT from the same donor in two independent clinical trials developed extended-spectrum beta-lactamase (ESBL)-producing E. coli septicemia following the procedure [115]. The patient with liver cirrhosis survived after intensive antibiotic therapy; however, the patient with myelodysplastic syndrome treated with allo-HSCT succumbed to sepsis.

It should be noted that the results of preclinical studies showing improved response to ICI following FMT involved the use of fecal material from patients who responded to ICI. Technically the FMT employed 
fecal materials that had already been "manipulated" in vivo, prior to donation. It, therefore, remains unknown if similar outcome would be attained with FMT from healthy donors without a cancer diagnosis and have not been previously exposed to ICI.

\section{Semi-selective modification of intestinal microbiome using antibiotics}

Results obtained from clinical and preclinical studies showing the detrimental effects of broad-spectrum antibiotics on the outcome of ICI treatment of cancer [85] argue for the semi-selective modification of the intestinal microbiome and the restricted use of broad-spectrum antibiotics in these patients. The association between the development of CDI and VRE and the use of antibiotics also suggests the need to avoid routine use of prophylactic antibiotics in these patients. A careful choice of antibiotics may be preferable for patients who require antibiotic prophylaxis. Prophylaxis using rifaximin, a minimally absorbed broad-spectrum antibiotic, may be the answer. Rifaximin was associated with lesser disturbance to the intestinal microbial diversity, compared to ciprofloxacin and metronidazole in allo-HSCT recipients of hematologic malignancy patients [116, 117]. These patients also showed higher levels of urinary 3-indoxyl sulfate that correlated with intestinal increase in Clostridales involved in the production of SCFA. Transplant outcome was also more favorable, with lower incidence of GvHD and transplant-related mortality. Rifaximin prophylaxis to reduce anticancer treatment-associated gastrointestinal toxicity and diarrhea in colon adenocarcinoma (NCT04003181) and stage I-III human epidermal growth factor receptor 2 (HER2)-positive breast cancer (NCT04249622) clinical trials are currently active. A randomized placebo-control trial of rifaximin prophylaxis to reduce infection in CRC patients (NCT03563586) is also recruiting participants.

Other beneficial effects of rifaximin include protection against entero-infections, especially CDI, and restoration of mucosal barrier. Given the common occurrence of CDI in cancer patients during and after treatment, rifaximin prophylaxis may protect against recurrent/refractory CDI. In addition, rifaximin modulates bacterial metabolic function to preserve intestinal barrier, inhibit bacterial attachment, and reduce mucosal inflammation. In liver cirrhosis, rifaximin improves mucosal barrier function and reduce the translocation of enteric pathogens, endotoxin, and other products such as ammonia to prevent inflammation and the development of hepatic encephalopathy [118]. Similar benefits have been observed when sickle cell disease (SCD) patients were given rifaximin for 6 months [119]. There was a shift towards increased abundance of Bacteroides and Akkermansia in the intestine. Rifaximin improved intestinal permeability, decreased intestinal injury, and reduced the translocation of LPS [120]. These improvements in the intestinal pathophysiology reversed upon discontinuation of the rifaximin [121].

Although rifaximin preserves microbial diversity, improves gut barrier function and reduces inflammation, the beneficial effects are not seen universally across different disease types. When rifaximin was administered to human immunodeficiency virus (HIV) patients to modify the abundance of Prevotella and Succinivibrio, and depletion of Bacteroides, Faecalibacterium, and Roseburia [122], there were only marginal changes in the intestinal inflammation, microbial translocation, and Tcell activation [123]. Similarly, although rifaximin altered the microbial diversity with a reduction in Ruminococcaceae members and increase in Bacteroides in common variable immunodeficiency (CVID), the changes were transient, and rifaximin did not affect serum LPS and immune function [124].

\section{Biologic modification of intestinal barrier}

modification of intestinal barrier has been practiced for many years using probiotic and prebiotic to promote the proliferation of intestinal microbes involved in SCFA production. However, due to variability in the contents of these agents, their microbial end-results cannot be consistently predicted.

Replenishing or enriching the intestinal microbiome with "good" microbes may be an alternative option. The Gram-negative mucin-degrading anaerobe, Akkermansia muciniphila, may fit the purpose. A. muciniphila fortifies the mucosal layer and plays an important role in the functional maintenance of the gut barrier [125]. A. muciniphila modulates immune homeostasis by activating TLR2-expressing cells [126]. It has a weak activating effect on TLR4 and little effect on TLR5, TLR9 or Nucleotide-binding oligomerization domain-containing protein (NOD)2 receptors. Several studies have shown an inverse relationship between diseased states and $A$. muciniphila abundance in the intestine [92, 125, 127-130]. A. muciniphila supplementation restores gut barrier function, improves inflammatory state, and protects against cancer, obesity, type 2 diabetes, hypertension, and liver diseases. In a proof-of-concept human trial of metabolic syndrome, the subjects given 3 months of oral supplementation of live or pasteurized A. muciniphila showed improvement of several metabolic parameters including insulin sensitivity [127]. In addition, A. muciniphila-treated patients had improved gut barrier functions, with significantly lower plasma LPS, white blood cell counts and inflammatory markers. The potential role of A. muciniphila in improving ICI therapy was demonstrated in NSCLC and RCC. Patients with increased abundance of intestinal $A$. muciniphila responded favorably to anti-PD-1 treatment [92]. Antibiotic-treated RET melanoma-bearing mice that 
did not respond to PD-1 blockade showed responsiveness after natural intestinal recolonization and supplementation of A. muciniphila. Similarly, in Lewis lung carcinoma mice model oral gavage of $A$. muciniphila increased the efficacy of PD-1 blockade. A. muciniphila induced DCs to secrete IL-12. As a result, increased CCR9 ${ }^{+} \mathrm{CXCR} 3^{+} \mathrm{CD} 4^{+} \mathrm{T}$ lymphocytes were recruited to the tumor microenvironment to augment the effect of anti-PD-1 antibody. Thus, A. muciniphila improves intestinal barrier function and cancer treatment outcomes.

Unfortunately, an overgrowth or over-abundance of $A$ muciniphila may be detrimental. A. muciniphila degrades mucin. Its abundance may paradoxically induce damage to the mucosal barrier, promote intestinal permeability, and facilitate translocation of endotoxin resulting in negative pathological outcomes. Abundance of A. muciniphila was shown to promote epithelial access following mucus degradation and trigger lethal colitis by Citrobacter rodentium in gnotobiotic mice [131]. Additional negative effects of $A$. muciniphila enrichment was observed in a hormone receptor-positive breast cancer mice model [132]. Antibiotic-mediated reduction in gut microbiota diversity and enrichment of $A$. muciniphila promoted increased abundance of macrophages and inflammatory chemokines in the mammary gland, mammary tumor, and blood. There was increased metastatic dissemination of tumor cells into the blood, lymph nodes, and to lungs. The threshold dose needed for A. muciniphila to enhance cancer treatment response without inducing negative effects will, therefore, need to be established before any isolated supplementation or enrichment is attempted to improve the outcome of cancer therapy.

A. muciniphila abundantly expresses on its outer membrane a $32 \mathrm{kDa}$ surface protein with pili-like structure called AMUC_1100 [126, 133]. AMUC_1100 may facilitate direct interaction between $A$. muciniphila and gut epithelial cells and modulate immune response via TLR2 pathway. Treatment of obese and diabetic mice with recombinant AMUC_1100 lowered plasma highdensity lipoprotein (HDL), enhanced glucose tolerance, and improved gut permeability, and increased gut tightjunction markers claudin 3 and occludin [126]. In a mouse model of colitis-associated CRC, AMUC_1100 delayed tumor formation and reduced tumor number and size [134]. AMUC_1100 increased $\mathrm{CD}^{+} \mathrm{T}$ cells and TNF- $\alpha$ secretion in colon. In addition, there was a downregulation of proliferative markers $\gamma \mathrm{H} 2 \mathrm{AX}$ and Ki67, and reduction in PD-1+ T cells in AMUC_1100treated CAC mice. Given the potential benefits and risks associated with $A$. muciniphila supplementation in cancer therapy, AMUC_1100 may be a safer alternative to using intact organisms.

Instead of recombinant AMUC_1100, A. muciniphiladerived extracellular vesicles (AmEVs) may be another option. In obese mice, AmEVs treatment improved gut barrier integrity by increasing expressions of occludin, zona occludens and claudin 5, and reduced inflammation due to less production of TNF- $\alpha$ and IL-6 $[135,136]$.

\section{Conclusions}

Through animal and clinical studies, we have in the last decade gained tremendous insights into the role of gut microbiome in cancer development, progression, and treatment. Although there is a general consensus that certain bacteria such as Faecalibacterium and A. muciniphila are associated with superior immune response and cancer treatment efficacy, and Proteobacteria with poor treatment response, there is still a big knowledge gap in the mechanistic interactions of microbiota with host tissues under different conditions and with other microbes such as viruses, fungi, and parasites. Analysis of microbiome using $16 \mathrm{~s}$ rRNA sequencing or metagenomic shotgun sequencing will not capture all the species and thus miss those that are in minority. These minor microbial florae can significantly influence tissue homeostasis. Oversimplified associations of a group of microbes in certain diseased or therapeutic condition can be misleading.

Disease and therapeutic interventions not only cause dysbiosis and gut permeability, they also affect microbiota and epithelial barrier integrity in other sites. Therefore, the synergistic effects of microbiome of different organs in immune function regulation/dysregulation and therapeutic outcomes should also be considered. In addition, cancer treatment strategies based on gut microbiota results in humanized mice models or mice with transplanted human tumors may not be directly translational and can be confounding. Transplanted tumors may also not possess all its original characteristics necessary to influence microbiome changes and elicit unfavorable immune responses [137]. Thus, without a more comprehensive understanding of the interplay between microbiota in different tissues, and the knowledge of how to modulate them for specific immune response, it would remain a challenge to formulate an optimal cancer therapeutic strategy.

\footnotetext{
Abbreviations

ALL: Acute lymphoblastic leukemia; Allo-HSCT: Allogeneic hematopoietic stem cell transplant; AmEV: A. muciniphila-derived extracellular vesicles; AML: Acute myeloid leukemia; APC: Adenomatous polyposis coli; ATP: Adenosine triphosphate; CAR T: Chimeric antigen receptor T; CCR: C-C Motif chemokine receptor; CDI: Clostridium difficile infection; CDT: Cytolethal distending toxin; CRC: Colorectal cancer; CTLA: T Iymphocyte-associated antigen; CVID: Combined variable immune deficiency; CXCL: Chemokine (C-X-C motif) ligand; DAMP: Damage-associated molecular pattern; DC: Dendritic cell; DNA: Deoxyribonucleic acid; ESLB: Extended-spectrum beta-lactamase; FMT: Fecal microbiota transplant; GvHD: Graft-versus-host disease; HDL: Highdensity lipoprotein; HIV: Human immunodeficiency virus; HMGB1: High mobility group box 1; ICl: Immune checkpoint inhibitor; IL: Interleukin; LPS: Lipopolysaccharides; MALT: Mucosal-associated lymphoid tissue; MHC: Major histocompatibility complex; MUC: Mucin; MYD88: Myeloid differentiation primary response protein 88; NF-KB: Nuclear Factor kappa light chain enhancer of activated B cells; NKT: Natural killer T; NOD: Nucleotide-
} 
binding oligomerization domain-containing protein; NSCLC: Non-small cell lung cancer; PAMP: Pathogen-associated molecular pattern; PD: Programmed death receptor; PD-L: Programmed death receptor ligand; PPARү: Peroxisome proliferator-activated receptor gamma; PRR: Pattern recognition receptor; RCC: Renal cell carcinoma; RNA: Ribonucleic acid; SCFA: Short-chain fatty acid; Tet2: Ten-eleven translocation-2; Th: T-helper; TIGIT: T cell immunoreceptor with Ig and ITIM domains; TLR: Toll-like receptor; TNF: Tumor necrosis factor; $T_{\text {reg: }}$ T regulatory; VRE: Vancomycinresistant enterococci

\section{Acknowledgements}

None.

\section{Authors' contributions}

Both DD and SHL were involved in formulating the presentation, performing the research, and writing the manuscript. The authors read and approved the final manuscript.

\section{Funding}

None.

\section{Availability of data and materials}

Not applicable.

Ethics approval and consent to participate

Not applicable.

\section{Consent for publication}

Agreed between both authors.

\section{Competing interests}

None.

Received: 27 July 2020 Accepted: 5 August 2020

Published online: 12 August 2020

\section{References}

1. Deplancke B, Gaskins HR. Microbial modulation of innate defense: goblet cells and the intestinal mucus layer. Am J Clin Nutr. 2001;73:1131S-41S.

2. Ivanov II, Atarashi K, Manel N, Brodie EL, Shima T, Karaoz U, Wei D, Goldfarb KC, Santee CA, Lynch SV. Induction of intestinal Th17 cells by segmented filamentous bacteria. Cell. 2009;139:485-98.

3. Peng L, Li Z, Green RS, Holzman IR, Lin J. Butyrate enhances the intestinal barrier by facilitating tight junction assembly via activation of AMP-activated protein kinase in Caco-2 cell monolayers. J Nutr. 2009;139:1619-25.

4. Wang $H$, Wang $P$, Wang $X$, Wan Y, Liu Y. Butyrate enhances intestinal epithelial barrier function via up-regulation of tight junction protein Claudin-1 transcription. Dig Dis Sci. 2012;57:3126-35.

5. Litvak Y, Byndloss MX, Bäumler AJ. Colonocyte metabolism shapes the gut microbiota. Science. 2018;362:eaat9076.

6. Sekirov I, Russell SL, Antunes LCM, Finlay BB. Gut microbiota in health and disease. Physiol Rev. 2010;90:859-904

7. Guerra L, Guidi R, Frisan T. Do bacterial genotoxins contribute to chronic inflammation, genomic instability and tumor progression? FEBS J. 2011;278: 4577-88.

8. Dapito DH, Mencin A, Gwak G, Pradere J, Jang M, Mederacke I, Caviglia JM, Khiabanian H, Adeyemi A, Bataller R. Promotion of hepatocellular carcinoma by the intestinal microbiota and TLR4. Cancer Cell. 2012;21:504-16.

9. Paulos CM, Wrzesinski C, Kaiser A, Hinrichs CS, Chieppa M, Cassard L, Palmer DC, Boni A, Muranski P, Yu Z. Microbial translocation augments the function of adoptively transferred self/tumor-specific CD8 T cells via TLR4 signaling. J Clin Invest. 2007;117:2197-204.

10. Paulos CM, Kaiser A, Wrzesinski C, Hinrichs CS, Cassard L, Boni A, Muranski P, Sanchez-Perez L, Palmer DC, Yu Z. Toll-like receptors in tumor immunotherapy. Clin Cancer Res. 2007;13:5280-9.

11. Yu T, Guo F, Yu Y, Sun T, Ma D, Han J, Qian Y, Kryczek I, Sun D, Nagarsheth N. Fusobacterium nucleatum promotes chemoresistance to colorectal cancer by modulating autophagy. Cell. 2017;170:548-563.e16.

12. lida N, Dzutsev A, Stewart CA, Smith L, Bouladoux N, Weingarten RA, Molina DA, Salcedo R, Back T, Cramer S. Commensal bacteria control cancer response to therapy by modulating the tumor microenvironment. Science. 2013;342:967-70.

13. Shang F, Liu H. Fusobacterium nucleatum and colorectal cancer: a review. World J Gastrointest Oncol. 2018;10:71.

14. Kostic AD, Chun E, Robertson L, Glickman JN, Gallini CA, Michaud M, Clancy TE, Chung DC, Lochhead P, Hold GL. Fusobacterium nucleatum potentiates intestinal tumorigenesis and modulates the tumor-immune microenvironment. Cell Host Microbe. 2013;14:207-15.

15. Fukugaiti MH, Ignacio A, Fernandes MR, Ribeiro Júnior U, Nakano V, AvilaCampos MJ. High occurrence of Fusobacterium nucleatum and Clostridium difficile in the intestinal microbiota of colorectal carcinoma patients. Brazilian J Microbiol. 2015;46:1135-40.

16. Warren RL, Freeman DJ, Pleasance S, Watson P, Moore RA, Cochrane K, Allen-Vercoe E, Holt RA. Co-occurrence of anaerobic bacteria in colorectal carcinomas. Microbiome. 2013:1:16.

17. Yu J, Feng Q, Wong SH, Zhang D, Liang QY, Qin Y, Tang L, Zhao H, Stenvang J, Li Y. Metagenomic analysis of faecal microbiome as a too towards targeted non-invasive biomarkers for colorectal cancer. Gut. 2017; 66:70-8.

18. Cani PD. Human gut microbiome: hopes, threats and promises. Gut. 2018; 67:1716-25.

19. Grivennikov SI, Wang K, Mucida D, Stewart CA, Schnabl B, Jauch D, Taniguchi K, Yu G, Österreicher CH, Hung KE. Adenoma-linked barrier defects and microbial products drive IL-23/IL-17-mediated tumour growth. Nature. 2012;491:254-8.

20. Velcich A, Yang W, Heyer J, Fragale A, Nicholas C, Viani S, Kucherlapati R, Lipkin M, Yang K, Augenlicht L. Colorectal cancer in mice genetically deficient in the mucin Muc2. Science. 2002;295:1726-9.

21. Ma C, Han M, Heinrich B, Fu Q, Zhang Q, Sandhu M, Agdashian D, Terabe M, Berzofsky JA, Fako V. Gut microbiome-mediated bile acid metabolism regulates liver cancer via NKT cells. Science. 2018;360:eaan5931.

22. Chng KR, Chan SH, Ng AHQ, Li C, Jusakul A, Bertrand D, Wilm A, Choo SP, Tan DMY, Lim KH. Tissue microbiome profiling identifies an enrichment of specific enteric bacteria in Opisthorchis viverrini associated cholangiocarcinoma. EBioMedicine. 2016;8:195-202.

23. Ochi A, Nguyen AH, Bedrosian AS, Mushlin HM, Zarbakhsh S, Barilla R, Zambirinis CP, Fallon NC, Rehman A, Pylayeva-Gupta Y. MyD88 inhibition amplifies dendritic cell capacity to promote pancreatic carcinogenesis via Th2 cells. J Exp Med. 2012;209:1671-87.

24. Pushalkar S, Hundeyin M, Daley D, Zambirinis CP, Kurz E, Mishra A, Mohan $\mathrm{N}$, Aykut B, Usyk M, Torres LE. The pancreatic cancer microbiome promotes oncogenesis by induction of innate and adaptive immune suppression. Cancer Discov. 2018:8:403-16.

25. Riquelme E, Zhang Y, Zhang L, Montiel M, Zoltan M, Dong W, Quesada P. Sahin I, Chandra V, San Lucas A. Tumor microbiome diversity and composition influence pancreatic cancer outcomes. Cell. 2019;178:795806.e12.

26. Geller LT, Barzily-Rokni M, Danino T, Jonas OH, Shental N, Nejman D, Gavert $\mathrm{N}$, Zwang Y, Cooper ZA, Shee K. Potential role of intratumor bacteria in mediating tumor resistance to the chemotherapeutic drug gemcitabine. Science. 2017:357:1156-60.

27. Jin C, Lagoudas GK, Zhao C, Bullman S, Bhutkar A, Hu B, Ameh S, Sandel D, Liang XS, Mazzilli S. Commensal microbiota promote lung cancer development via $\gamma \delta$ T cells. Cell. 2019;176:998-1013.e16.

28. Zhuang $H$, Wang $Y$, Zhang $Y$, Zhao M, Liang G, Zhang M, Li Y, Zhao J, Gao $Y$, Zhou Y. Dysbiosis of the gut microbiome in lung cancer. Front Cell Infect Microbiol. 2019:9:112.

29. Zhang W, Zhao S, Luo J, Dong X, Hao Y, Li H, Shan L, Zhou Y, Shi H, Zhang $Z$. Alterations of fecal bacterial communities in patients with lung cancer. Am J Transl Res. 2018:10:3171-85.

30. Gui Q, Li H, Wang A, Zhao X, Tan Z, Chen L, Xu K, Xiao C. The association between gut butyrate-producing bacteria and non-small-cell lung cancer. J Clin Lab Anal. 2020;29:e23318.

31. Manzo VE, Bhatt AS. The human microbiome in hematopoiesis and hematologic disorders. Blood. 2015;126:311-8.

32. Meisel M, Hinterleitner R, Pacis A, Chen L, Earley ZM, Mayassi T, Pierre JF, Ernest JD, Galipeau HJ, Thuille N. Microbial signals drive pre-leukaemic myeloproliferation in a Tet2-deficient host. Nature. 2018:557:580-4.

33. Shen Q, Zhang Q, Shi Y, Shi Q, Jiang Y, Gu Y, Li Z, Li X, Zhao K, Wang C. Tet2 promotes pathogen infection-induced myelopoiesis through mRNA oxidation. Nature. 2018;554:123-7. 
34. Zhang Q, Zhao K, Shen Q, Han Y, Gu Y, Li X, Zhao D, Liu Y, Wang C, Zhang $X$. Tet2 is required to resolve inflammation by recruiting Hdac2 to specifically repress IL-6. Nature. 2015;525:389-93.

35. Blijlevens N, Van't Land B, Donnelly JP, M'Rabet L, De Pauw BE. Measuring mucosal damage induced by cytotoxic therapy. Support Care Cancer. 2004; 12:227-33.

36. Sundström GM, Wahlin A, Nordin-Andersson I, Suhr OB. Intestinal permeability in patients with acute myeloid leukemia. Eur J Haematol. 1998; 61:250-4.

37. Song Y, Gyarmati P. Bacterial translocation in acute lymphocytic leukemia. PLoS One. 2019;14:e0214526.

38. Rajagopala SV, Yooseph S, Harkins DM, Moncera KJ, Zabokrtsky KB, Torralba MG, Tovchigrechko A, Highlander SK, Pieper R, Sender L. Gastrointestinal microbial populations can distinguish pediatric and adolescent acute lymphoblastic leukemia (ALL) at the time of disease diagnosis. BMC Genomics. 2016;17:635

39. Bai L, Zhou P, Li D, Ju X. Changes in the gastrointestinal microbiota of children with acute lymphoblastic leukaemia and its association with antibiotics in the short term. J Med Microbiol. 2017;66:1297-307.

40. Chua LL, Rajasuriar R, Lim YAL, Woo YL, Ariffin H. Temporal changes in gut microbiota profile in children with acute lymphoblastic leukemia prior to commencement-, during-, and post-cessation of chemotherapy. BMC Cancer. 2020;20:1-11.

41. Shelburne SA, Ajami NJ, Chibucos MC, Beird HC, Tarrand J, Galloway-Pena J, Albert N, Chemaly RF, Ghantoji SS, Marsh L. Implementation of a pangenomic approach to investigate holobiont-infecting microbe interaction: a case report of a leukemic patient with invasive mucormycosis. PLoS One. 2015;10:e0139851.

42. Hakim H, Dallas R, Wolf J, Tang L, Schultz-Cherry S, Darling V, Johnson C, Karlsson EA, Chang T, Jeha S. Gut microbiome composition predicts infection risk during chemotherapy in children with acute lymphoblastic leukemia. Clin Infect Dis. 2018;67:541-8.

43. Yamamoto ML, Schiestl RH. Lymphoma caused by intestinal microbiota. Int J Environ Res Public Health. 2014;11:9038-49.

44. Aigelsreiter A, Gerlza T, Deutsch AJ, Leitner E, Beham-Schmid C, Beham A, Popper H, Borel N, Pospischil A, Raderer M. Chlamydia psittaci infection in nongastrointestinal extranodal MALT lymphomas and their precursor lesions. Am J Clin Pathol. 2011;135:70-5.

45. Schöllkopf C, Melbye M, Munksgaard L, Smedby KE, Rostgaard K, Glimelius B, Chang ET, Roos G, Hansen M, Adami H. Borrelia infection and risk of nonHodgkin lymphoma. Blood. 2008;111:5524-9.

46. Chang CM, Landgren O, Koshiol J, Björkholm M, Löve TJ, Kristinsson SY. Borrelia and subsequent risk of solid tumors and hematologic malignancies in Sweden. Int J Cancer. 2012;131:2208-9.

47. Ponzoni M, Ferreri AJ, Mappa S, Pasini E, Govi S, Facchetti F, Fanoni D, Tucci A, Vino A, Doglioni C. Prevalence of Borrelia burgdorferi infection in a series of 98 primary cutaneous lymphomas. Oncologist. 2011;16:1582-8.

48. Peled JU, Devlin SM, Staffas A, Lumish M, Khanin R, Littmann ER, Ling L, Kosuri S, Maloy M, Slingerland JB. Intestinal microbiota and relapse after hematopoietic-cell transplantation. J Clin Oncol. 2017;35:1650.

49. Nearing JT, Connors J, Whitehouse S, Van Limbergen J, Macdonald T, Kulkarni K, Langille M. Infectious complications are associated with alterations in the gut microbiome in pediatric patients with acute lymphoblastic leukemia. Front Cell Infect Microbiol. 2019;9:28.

50. Montassier E, Al-Ghalith GA, Ward T, Corvec S, Gastinne T, Potel G, Moreau P, de la Cochetiere MF, Batard E, Knights D. Pretreatment gut microbiome predicts chemotherapy-related bloodstream infection. Genome Med. 2016;8:49.

51. Roland BC, Ciarleglio MM, Clarke JO, Semler JR, Tomakin E, Mullin GE, Pasricha PJ. Small intestinal transit time is delayed in small intestinal bacterial overgrowth. J Clin Gastroenterol. 2015:49:571-6.

52. Cherfils-Vicini J, Platonova S, Gillard M, Laurans L, Validire P, Caliandro R, Magdeleinat P, Mami-Chouaib F, Dieu-Nosjean M, Fridman W. Triggering of TLR7 and TLR8 expressed by human lung cancer cells induces cell survival and chemoresistance. J Clin Invest. 2010;120:1285-97.

53. Ilvesaro JM, Merrell MA, Swain TM, Davidson J, Zayzafoon M, Harris KW, Selander KS. Toll like receptor-9 agonists stimulate prostate cancer invasion in vitro. Prostate. 2007;67:774-81.

54. Ren T, Wen Z, Liu Z, Liang Y, Guo Z, Xu L. Functional expression of TLR9 is associated to the metastatic potential of human lung cancer cell. Cancer Biol Ther. 2007;6:1704-9.
55. Alexander JL, Wilson ID, Teare J, Marchesi JR, Nicholson JK, Kinross JM. Gut microbiota modulation of chemotherapy efficacy and toxicity. Nat Rev Gastroenterol Hepatol. 2017;14:356-65.

56. Viaud S, Saccheri F, Mignot G, Yamazaki T, Daillère R, Hannani D, Enot DP, Pfirschke C, Engblom C, Pittet MJ. The intestinal microbiota modulates the anticancer immune effects of cyclophosphamide. Science. 2013;342:971-6.

57. Stringer AM, Gibson RJ, Logan RM, Bowen JM, Yeoh AS, Keefe DM. Faecal microflora and $\beta$-glucuronidase expression are altered in an irinotecaninduced diarrhea model in rats. Cancer Biol Ther. 2008;7:1919-25.

58. Kurita A, Kado S, Matsumoto T, Asakawa N, Kaneda N, Kato I, Uchida K, Onoue M, Yokokura T. Streptomycin alleviates irinotecan-induced delayedonset diarrhea in rats by a mechanism other than inhibition of $\beta$ glucuronidase activity in intestinal lumen. Cancer Chemother Pharmacol. 2011;67:201-13.

59. Kodawara T, Higashi T, Negoro Y, Kamitani Y, Igarashi T, Watanabe K, Tsukamoto H, Yano R, Masada M, Iwasaki H. The inhibitory effect of ciprofloxacin on the $\beta$-glucuronidase-mediated deconjugation of the irinotecan metabolite SN-38-G. Basic Clin Pharmacol Toxicol. 2016;118:333-7.

60. Kong R, Liu T, Zhu X, Ahmad S, Williams AL, Phan AT, Zhao H, Scott JE, Yeh L, Wong ST. Old drug new use-amoxapine and its metabolites as potent bacterial $\beta$-glucuronidase inhibitors for alleviating cancer drug toxicity. Clin Cancer Res. 2014;20:3521-30.

61. Bodiga VL, Bodiga S, Surampudi S, Boindala S, Putcha U, Nagalla B, Subramaniam K, Manchala R. Effect of vitamin supplementation on cisplatininduced intestinal epithelial cell apoptosis in Wistar/NIN rats. Nutrition. 2012; 28:572-80.

62. Emoto M, Kawarabayashi T, Hachisuga T, Eguchi F, Shirakawa K. Clostridium difficile colitis associated with cisplatin-based chemotherapy in ovarian cancer patients. Gynecol Oncol. 1996;61:369-72.

63. Karasawa T, Steyger PS. An integrated view of cisplatin-induced nephrotoxicity and ototoxicity. Toxicol Lett. 2015;237:219-27.

64. Gui QF, Lu HF, Zhang CX, Xu ZR, Yang YH. Well-balanced commensal microbiota contributes to anti-cancer response in a lung cancer mouse model. Genet Mol Res. 2015;14:5642-51.

65. Pflug N, Kluth S, Vehreschild JJ, Bahlo J, Tacke D, Biehl L, Eichhorst B, Fischer K, Cramer P, Fink A. Efficacy of antineoplastic treatment is associated with the use of antibiotics that modulate intestinal microbiota. Oncoimmunology. 2016;5:e1150399.

66. Perales-Puchalt A, Perez-Sanz J, Payne KK, Svoronos N, Allegrezza MJ, Chaurio RA, Anadon C, Calmette J, Biswas S, Mine JA. Frontline science: microbiota reconstitution restores intestinal integrity after cisplatin therapy. J Leukoc Biol. 2018;103:799-805.

67. Campbell KC, Rybak LP, Meech RP, Hughes L. D-methionine provides excellent protection from cisplatin ototoxicity in the rat. Hear Res. 1996;102: 90-8.

68. Vuyyuri SB, Hamstra DA, Khanna D, Hamilton CA, Markwart SM, Campbell KC, Sunkara P, Ross BD, Rehemtulla A. Evaluation of D-methionine as a novel oral radiation protector for prevention of mucositis. Clin Cancer Res. 2008;14:2161-70.

69. Loman BR, Jordan KR, Haynes B, Bailey MT, Pyter LM. Chemotherapyinduced neuroinflammation is associated with disrupted colonic and bacterial homeostasis in female mice. Sci Rep. 2019;9:1-16.

70. Ramakrishna C, Corleto J, Ruegger PM, Logan GD, Peacock BB, Mendonca S, Yamaki S, Adamson T, Ermel R, McKemy D. Dominant role of the gut microbiota in chemotherapy induced neuropathic pain. Sci Rep. 2019;9:1-16.

71. Husain A, Aptaker L, Spriggs DR, Barakat RR. Gastrointestinal toxicity and Clostridium Difficile diarrhea in patients treated with paclitaxel-containing chemotherapy regimens. Gynecol Oncol. 1998;71:104-7.

72. Masciullo V, Mainenti S, Lorusso D, Margariti PA, Scambia G. Lethal Clostridium difficile colitis associated with paclitaxel and carboplatin chemotherapy in ovarian carcinoma: case report and review of the literature. Obstet Gynecol Int. 2010;2010:749789.

73. Carvalho R, Vaz A, Pereira FL, Dorella F, Aguiar E, Chatel J, Bermudez L, Langella P, Fernandes G, Figueiredo H. Gut microbiome modulation during treatment of mucositis with the dairy bacterium Lactococcus lactis and recombinant strain secreting human antimicrobial PAP. Sci Rep. 2018;8:1-10.

74. Pereira VB, Melo AT, Assis-Júnior EM, Wong DV, Brito GA, Almeida PR, Ribeiro RA, Lima-Júnior RC. A new animal model of intestinal mucositis induced by the combination of irinotecan and 5-fluorouracil in mice. Cancer Chemother Pharmacol. 2016;77:323-32. 
75. Anand A, Glatt AE. Clostridium difficile infection associated with antineoplastic chemotherapy: a review. Clin Infect Dis. 1993;17:109-13.

76. Chamorro RM, Blanch RS, Vidal MJM, España MAG, Pérez MJR, de la Haba Rodríguez JR, Aguilar EA. Pseudomembranous colitis associated with chemotherapy with 5-fluorouracil. Clin Transl Oncol. 2005;7:258-61.

77. Ferreira TM, Leonel AJ, Melo MA, Santos RR, Cara DC, Cardoso VN, Correia Ml, Alvarez-Leite J. Oral supplementation of butyrate reduces mucositis and intestinal permeability associated with 5 -fluorouracil administration. Lipids. 2012;47:669-78.

78. Yuan L, Zhang S, Li H, Yang F, Mushtaq N, Ullah S, Shi Y, An C, Xu J. The influence of gut microbiota dysbiosis to the efficacy of 5-fluorouracil treatment on colorectal cancer. Biomed Pharmacother. 2018;108:184-93.

79. Daillère R, Vétizou M, Waldschmitt N, Yamazaki T, Isnard C, Poirier-Colame V, Duong CP, Flament C, Lepage P, Roberti MP. Enterococcus hirae and Barnesiella intestinihominis facilitate cyclophosphamide-induced therapeutic immunomodulatory effects. Immunity. 2016:45:931-43.

80. Kim YS, Kim J, Park S. High-throughput 165 rRNA gene sequencing reveals alterations of mouse intestinal microbiota after radiotherapy. Anaerobe. 2015;33:1-7.

81. Nam Y, Kim HJ, Seo J, Kang SW, Bae J. Impact of pelvic radiotherapy on gut microbiota of gynecological cancer patients revealed by massive pyrosequencing. PLoS One. 2013;8:e82659.

82. Ferreira MR, Andreyev HJN, Mohammed K, Truelove L, Gowan SM, Li J, Gulliford SL, Marchesi JR, Dearnaley DP. Microbiota-and radiotherapyinduced gastrointestinal side-effects (MARS) study: a large pilot study of the microbiome in acute and late-radiation enteropathy. Clin Cancer Res. 2019; 25:6487-500.

83. Yi M, Yu S, Qin S, Liu Q, Xu H, Zhao W, Chu Q, Wu K. Gut microbiome modulates efficacy of immune checkpoint inhibitors. J Hematol Oncol. 2018; 11:47.

84. Abid MB. Could the menagerie of the gut microbiome really cure cancer? Hope or hype. J Immunother Cancer. 2019;7:92.

85. Ahmed J, Kumar A, Parikh K, Anwar A, Knoll BM, Puccio C, Chun H, Fanucchi M, Lim SH. Use of broad-spectrum antibiotics impacts outcome in patients treated with immune checkpoint inhibitors. Oncoimmunology. 2018;7: e1507670.

86. Vétizou M, Pitt JM, Daillère R, Lepage P, Waldschmitt N, Flament C, Rusakiewicz S, Routy B, Roberti MP, Duong CP. Anticancer immunotherapy by CTLA-4 blockade relies on the gut microbiota. Science. 2015;350:1079-84.

87. Wang F, Yin Q, Chen L, Davis MM. Bifidobacterium can mitigate intestinal immunopathology in the context of CTLA-4 blockade. Proc Natl Acad Sci. 2018;115:157-61.

88. Dubin K, Callahan MK, Ren B, Khanin R, Viale A, Ling L, No D, Gobourne A, Littmann E, Huttenhower C. Intestinal microbiome analyses identify melanoma patients at risk for checkpoint-blockade-induced colitis. Nat Commun. 2016;7:10391.

89. Chaput N, Lepage P, Coutzac C, Soularue E, Le Roux K, Monot C, Boselli L, Routier E, Cassard L, Collins M. Baseline gut microbiota predicts clinical response and colitis in metastatic melanoma patients treated with ipilimumab. Ann Oncol. 2017;28:1368-79.

90. Matson V, Fessler J, Bao R, Chongsuwat T, Zha Y, Alegre M, Luke JJ, Gajewski TF. The commensal microbiome is associated with anti-PD-1 efficacy in metastatic melanoma patients. Science. 2018;359:104-8.

91. Gopalakrishnan V, Spencer CN, Nezi L, Reuben A, Andrews MC, Karpinets TV, Prieto PA, Vicente D, Hoffman K, Wei SC. Gut microbiome modulates response to anti-PD-1 immunotherapy in melanoma patients. Science. 2018;359:97-103.

92. Routy B, Le Chatelier E, Derosa L, Duong CP, Alou MT, Daillère R, Fluckiger A, Messaoudene M, Rauber C, Roberti MP. Gut microbiome influences efficacy of PD-1-based immunotherapy against epithelial tumors. Science. 2018;359:91-7

93. Smith M, Littmann ER, Slingerland JB, Clurman A, Slingerland AE, Taur Y, Schluter J, Park JH, O'Cearbhaill R, Mailankody S. Intestinal microbiota composition prior to car t cell infusion correlates with efficacy and toxicity. Blood. 2018;132:3492.

94. Taur $Y$, Jeng RR, Perales M, Littmann ER, Morjaria S, Ling L, No D, Gobourne A, Viale A, Dahi PB. The effects of intestinal tract bacterial diversity on mortality following allogeneic hematopoietic stem cell transplantation. Blood. 2014;124:1174-82.

95. Peled JU, Gomes AL, Devlin SM, Littmann ER, Taur Y, Sung AD, Weber D, Hashimoto D, Slingerland AE, Slingerland JB. Microbiota as predictor of mortality in allogeneic hematopoietic-cell transplantation. N Engl J Med. 2020;382:822-34.

96. Ford CD, Gazdik MA, Lopansri BK, Webb B, Mitchell B, Coombs J, Hoda D, Petersen FB. Vancomycin-resistant Enterococcus colonization and bacteremia and hematopoietic stem cell transplantation outcomes. Biol Blood Marrow Transpl. 2017;23:340-6.

97. Moss EL, Falconer SB, Tkachenko E, Wang M, Systrom H, Mahabamunuge J, Relman DA, Hohmann EL, Bhatt AS. Long-term taxonomic and functional divergence from donor bacterial strains following fecal microbiota transplantation in immunocompromised patients. PLoS One. 2017;12: e0182585.

98. Taur Y, Coyte K, Schluter J, Robilotti E, Figueroa C, Gjonbalaj M, Littmann ER, Ling L, Miller L, Gyaltshen Y. Reconstitution of the gut microbiota of antibiotic-treated patients by autologous fecal microbiota transplant. Sci Transl Med. 2018;10:eaap9489.

99. Webb BJ, Brunner A, Ford CD, Gazdik MA, Petersen FB, Hoda D. Fecal microbiota transplantation for recurrent Clostridium difficile infection in hematopoietic stem cell transplant recipients. Transpl Infect Dis. 2016;18: 628-33.

100. Holler E, Butzhammer P, Schmid K, Hundsrucker C, Koestler J, Peter K, Zhu W, Sporrer D, Hehlgans T, Kreutz M. Metagenomic analysis of the stool microbiome in patients receiving allogeneic stem cell transplantation: loss of diversity is associated with use of systemic antibiotics and more pronounced in gastrointestinal graft-versus-host disease. Biol Blood Marrow Transpl. 2014;20:640-5.

101. Taur Y, Xavier JB, Lipuma L, Ubeda C, Goldberg J, Gobourne A, Lee YJ, Dubin KA, Socci ND, Viale A. Intestinal domination and the risk of bacteremia in patients undergoing allogeneic hematopoietic stem cell transplantation. Clin Infect Dis. 2012;55:905-14.

102. Biagi E, Zama D, Nastasi C, Consolandi C, Fiori J, Rampelli S, Turroni S, Centanni M, Severgnini M, Peano C. Gut microbiota trajectory in pediatric patients undergoing hematopoietic SCT. Bone Marrow Transplant. 2015;50: 992-8.

103. Jeng RR, Taur Y, Devlin SM, Ponce DM, Goldberg JD, Ahr KF, Littmann ER, Ling L, Gobourne AC, Miller LC. Intestinal Blautia is associated with reduced death from graft-versus-host disease. Biol Blood Marrow Transpl. 2015;21: 1373-83.

104. Jeng RR, Ubeda C, Taur Y, Menezes CC, Khanin R, Dudakov JA, Liu C, West ML, Singer NV, Equinda MJ. Regulation of intestinal inflammation by microbiota following allogeneic bone marrow transplantation. J Exp Med. 2012;209:903-11.

105. Gerbitz A, Schultz M, Wilke A, Linde H, Schölmerich J, Andreesen R, Holler E. Probiotic effects on experimental graft-versus-host disease: let them eat yogurt. Blood. 2004;103:4365-7.

106. Heimesaat MM, Nogai A, Bereswill S, Plickert R, Fischer A, Loddenkemper C, Steinhoff U, Tchaptchet S, Thiel E, Freudenberg MA. MyD88/TLR9 mediated immunopathology and gut microbiota dynamics in a novel murine model of intestinal graft-versus-host disease. Gut. 2010;59:1079-87.

107. Kakihana K, Fujioka Y, Suda W, Najima Y, Kuwata G, Sasajima S, Mimura I, Morita H, Sugiyama D, Nishikawa H. Fecal microbiota transplantation for patients with steroid-resistant acute graft-versus-host disease of the gut. Blood. 2016;128:2083-8.

108. Qi X, Li X, Zhao Y, Wu X, Chen F, Ma X, Zhang F, Wu D. Treating steroid refractory intestinal acute graft-vs-host disease with fecal microbiota transplantation: a pilot study. Front Immunol. 2018;9:2195.

109. Cheng Y, Phelps E, Ganapini V, Khan N, Ouyang F, Xu H, Khanna S, Tariq R, Friedman-Moraco RJ, Woodworth MH. Fecal microbiota transplantation for the treatment of recurrent and severe Clostridium difficile infection in solid organ transplant recipients: a multicenter experience. Am J Transplant. 2019; 19:501-11.

110. Kassam Z, Lee $\mathrm{CH}$, Yuan $Y$, Hunt RH. Fecal microbiota transplantation for Clostridium difficile infection: systematic review and meta-analysis. Am J Gastroenterol. 2013;108:500-8.

111. Gupta A, Cifu AS, Khanna S. Diagnosis and treatment of clostridium difficile infection. JAMA. 2018;320:1031-2.

112. Couturier-Maillard A, Secher T, Rehman A, Normand S, De Arcangelis A, Haesler R, Huot L, Grandjean T, Bressenot A, Delanoye-Crespin A. NOD2mediated dysbiosis predisposes mice to transmissible colitis and colorectal cancer. J Clin Invest. 2013;123:700-11.

113. Wang Y, Wiesnoski DH, Helmink BA, Gopalakrishnan V, Choi K, DuPont HL, Jiang Z, Abu-Sbeih $H$, Sanchez CA, Chang C. Fecal microbiota 
transplantation for refractory immune checkpoint inhibitor-associated colitis. Nat Med. 2018:24:1804-8.

114. De Castro CG, Ganc AJ, Ganc RL, Petrolli MS, Hamerschlack N. Fecal microbiota transplant after hematopoietic SCT: report of a successful case. Bone Marrow Transplant. 2015;50:145.

115. DeFilipp Z, Bloom PP, Torres Soto M, Mansour MK, Sater MR, Huntley MH, Turbett S, Chung RT, Chen Y, Hohmann EL. Drug-resistant E. coli bacteremia transmitted by fecal microbiota transplant. N Engl J Med. 2019;381:2043-50.

116. Weber D, Oefner PJ, Dettmer K, Hiergeist A, Koestler J, Gessner A, Weber M, Stämmler F, Hahn J, Wolff D. Rifaximin preserves intestinal microbiota balance in patients undergoing allogeneic stem cell transplantation. Bone Marrow Transplant. 2016;51:1087-92.

117. Weber D, Hiergeist A, Weber M, Dettmer K, Wolff D, Hahn J, Herr W, Gessner A, Holler E. Detrimental effect of broad-spectrum antibiotics on intestinal microbiome diversity in patients after allogeneic stem cell transplantation: lack of commensal sparing antibiotics. Clin Infect Dis. 2019;68:1303-10.

118. Bajaj JS, Barbara G, DuPont HL, Mearin F, Gasbarrini A, Tack J. New concepts on intestinal microbiota and the role of the non-absorbable antibiotics with special reference to rifaximin in digestive diseases. Dig Liver Dis. 2018;50: $741-9$.

119. Lim SH, Dutta D, Moore J. Rifaximin for sickle cell disease. Am J Hematol. 2019;94:E325-8,

120. Dutta D, Li K, Methe B, Lim SH. Rifaximin on intestinally-related pathologic changes in sickle cell disease. Am J Hematol. 2020;95:E83-6.

121. Lim SH, Dutta D. Clinicopathologic consequences following discontinuation of rifaximin in patients with sickle cell disease. Am J Hematol. 2020;95:E151-3.

122. Vazquez-Castellanos JF, Serrano-Villar S, Latorre A, Artacho A, Ferrus ML, Madrid N, Vallejo A, Sainz T, Martínez-Botas J, Ferrando-Martínez S. Altered metabolism of gut microbiota contributes to chronic immune activation in HIV-infected individuals. Mucosal Immunol. 2015;8:760-72.

123. Tenorio AR, Chan ES, Bosch RJ, Macatangay BJ, Read SW, Yesmin S, Taiwo B, Margolis DM, Jacobson JM, Landay AL. Rifaximin has a marginal impact on microbial translocation, T-cell activation and inflammation in HIV-positive immune non-responders to antiretroviral therapy-ACTG A5286. J Infect Dis. 2015;211:780-90.

124. Jørgensen SF, Macpherson ME, Bjørnetrø T, Holm K, Kummen M, Rashidi A, Michelsen AE, Lekva T, Halvorsen B, Trøseid M. Rifaximin alters gut microbiota profile, but does not affect systemic inflammation-a randomized controlled trial in common variable immunodeficiency. Sci Rep. 2019;9:1-10.

125. Dao MC, Everard A, Aron-Wisnewsky J, Sokolovska N, Prifti E, Verger EO, Kayser BD, Levenez F, Chilloux J, Hoyles L. Akkermansia muciniphila and improved metabolic health during a dietary intervention in obesity: relationship with gut microbiome richness and ecology. Gut. 2016;65: 426-36.

126. Plovier H, Everard A, Druart C, Depommier C, Van Hul M, Geurts L, Chilloux J, Ottman N, Duparc T, Lichtenstein L. A purified membrane protein from Akkermansia muciniphila or the pasteurized bacterium improves metabolism in obese and diabetic mice. Nat Med. 2017;23:107-13.

127. Depommier C, Everard A, Druart C, Plovier H, Van Hul M, Vieira-Silva S, Falony G, Raes J, Maiter D, Delzenne NM. Supplementation with Akkermansia muciniphila in overweight and obese human volunteers: a proof-of-concept exploratory study. Nat Med. 2019;25:1096-103.

128. Grander C, Adolph TE, Wieser V, Lowe P, Wrzosek L, Gyongyosi B, Ward DV, Grabherr F, Gerner RR, Pfister A. Recovery of ethanol-induced Akkermansia muciniphila depletion ameliorates alcoholic liver disease. Gut. 2018;67:891-901.

129. Li J, Zhao F, Wang Y, Chen J, Tao J, Tian G, Wu S, Liu W, Cui Q, Geng B. Gut microbiota dysbiosis contributes to the development of hypertension. Microbiome. 2017;5:14

130. Ponziani FR, Bhoori S, Castelli C, Putignani L, Rivoltini L, Del Chierico F, Sanguinetti M, Morelli D, Paroni Sterbini F, Petito V. Hepatocellular carcinoma is associated with gut microbiota profile and inflammation in nonalcoholic fatty liver disease. Hepatology. 2019;69:107-20.

131. Desai MS, Seekatz AM, Koropatkin NM, Kamada N, Hickey CA, Wolter M, Pudlo NA, Kitamoto S, Terrapon N, Muller A. A dietary fiber-deprived gut microbiota degrades the colonic mucus barrier and enhances pathogen susceptibility. Cell. 2016;167:1339-1353.e21.

132. Rosean CB, Bostic RR, Ferey JC, Feng T, Azar FN, Tung KS, Dozmorov MG, Smirnova E, Bos PD, Rutkowski MR. Preexisting commensal dysbiosis is a host-intrinsic regulator of tissue inflammation and tumor cell dissemination in hormone receptor-positive breast cancer. Cancer Res. 2019;79:3662-75.
133. Ottman N, Reunanen J, Meijerink M, Pietilä TE, Kainulainen V, Klievink J, Huuskonen L, Aalvink S, Skurnik M, Boeren S. Pili-like proteins of Akkermansia muciniphila modulate host immune responses and gut barrier function. PLoS One. 2017:12:e0173004.

134. Wang L, Tang L, Feng Y, Zhao S, Han M, Zhang C, Yuan G, Zhu J, Cao S, Wu Q, Li L, Zhang Z. A purified membrane protein from Akkermansia muciniphila or the pasteurised bacterium blunts colitis associated tumourigenesis by modulation of CD8 T cells in mice. Gut. 2020;23:320105.

135. Chelakkot C, Choi Y, Kim D, Park HT, Ghim J, Kwon Y, Jeon J, Kim M, Jee Y, Gho YS. Akkermansia muciniphila-derived extracellular vesicles influence gut permeability through the regulation of tight junctions. Exp Mol Med. 2018; 50:e450.

136. Ashrafian F, Shahryari A, Behrouzi A, Moradi HR, Lari A, Hadifar S, Yaghobfar R, Ahmadi Badi S, Vaziri F, Siadat SD. Akkermansia muciniphila-derived extracellular vesicles as a mucosal delivery vector for amelioration of obesity in mice. Front Microbiol. 2019;10:2155.

137. Zitvogel L, Pitt JM, Daillère R, Smyth MJ, Kroemer G. Mouse models in oncoimmunology. Nat Rev Cancer. 2016;16:759-73.

\section{Publisher's Note}

Springer Nature remains neutral with regard to jurisdictional claims in published maps and institutional affiliations.

\section{Ready to submit your research? Choose BMC and benefit from:}

- fast, convenient online submission

- thorough peer review by experienced researchers in your field

- rapid publication on acceptance

- support for research data, including large and complex data types

- gold Open Access which fosters wider collaboration and increased citations

- maximum visibility for your research: over $100 \mathrm{M}$ website views per year

At BMC, research is always in progress.

Learn more biomedcentral.com/submissions 